\title{
Electron Microscopy and Optical Characterization of Cadmium Sulphide Nanocrystals Deposited on the Patterned Surface of Diatom Biosilica
}

\author{
Timothy Gutu, ${ }^{1}$ Debra K. Gale, ${ }^{2}$ Clayton Jeffryes, ${ }^{2}$ Wei Wang, ${ }^{2}$ Chih-hung Chang, ${ }^{2}$ \\ Gregory L. Rorrer, ${ }^{2}$ and Jun Jiao ${ }^{1}$ \\ ${ }^{1}$ Department of Physics, Portland State University, OR 97201, USA \\ ${ }^{2}$ Department of Chemical Engineering, Oregon State University, Corvallis, 97331, USA
}

Correspondence should be addressed to Jun Jiao, jiaoj@pdx.edu

Received 18 December 2008; Accepted 19 February 2009

Recommended by Gong-Ru Lin

Intricately patterned biosilica obtained from the shell of unicellular algae called diatoms serve as novel templates for fabrication of optoelectronic nanostructures. In this study, the surface of diatom frustules that possessed hierarchical architecture ordered at the micro and nanoscale was coated with a nanostructured polycrystalline cadmium sulphide (CdS) thin film using a chemical bath deposition technique. The CdS thin film was composed of spherical nanoparticles with a diameter of about $75 \mathrm{~nm}$. The CdS nanoparticle thin film imparted new photoluminescent properties to the intricately patterned diatom nanostructure. The imparted photoluminescent properties were dependent on the CdS coverage onto the frustules surface. The intrinsic photoluminescent properties of the frustules were strongly quenched by the deposited CdS. The origin of PL spectra was discussed on the basis of the band theory and native defects.

Copyright (C) 2009 Timothy Gutu et al. This is an open access article distributed under the Creative Commons Attribution License, which permits unrestricted use, distribution, and reproduction in any medium, provided the original work is properly cited.

\section{Introduction}

The fabrication of nanomaterials with well-defined and controllable micro-to nanoscale features has been of great interest for chemical, optical, electronic, catalytic, environmental, and medical applications [1-3]. While bottom-up and top-down approaches have been extensively used to fabricate two-dimensional structures and devices, there is a need for inexpensive methods to mass-produce complex micro-to nanoscale structures with a variety of threedimensional (3D) morphologies at high degrees of precision, reproducibility, and chemical tailorability $[4,5]$ Nature is one inspirational source of nanostructures that can potentially meet this demand. For instance, diatoms are unicellular microalgae that form microscale silica cell walls called "frustules" which possess complex, intricately designed twoand three, dimensional nanopatterns. These patterns are species-specific and are faithfully reproduced upon cellular reproduction $[1,6-8]$.
The dielectric nature of the amorphous biosilica frustule has limited the use of these ornate nanostructures for optoelectronic device applications. Consequently, appreciable efforts have recently been underway to modify the silica, $\mathrm{SiO}_{2}$, into technologically more suitable functional materials while preserving the frustule shapes and morphologies. The frustule composition have been altered to or by functional materials such as $\mathrm{TiO}_{2}, \mathrm{BaTiO}_{3}, \mathrm{SrTiO}_{3}$, $\mathrm{MgO}, \mathrm{NiSO}_{4}, \mathrm{Zn}_{2} \mathrm{SiO}_{4}: \mathrm{Mn}, \mathrm{Y}_{2} \mathrm{SiO}_{5}: \mathrm{Eu}^{3+}$, and silicongermanium nanocomposites. Diatom frustules have also been chemically modified for the attachment of antibodies for medical applications. Sol-gel process, atomic layer deposition, chemical bath deposition, inkjet printing process, biosynthesis and low-temperature magnesiothermic reaction are some of the methods that have been used to modify the chemical composition of the frustules [9-16]. In this investigation, we explored a simple approach that utilized a scalable, low-cost chemical bath deposition (CBD) technique to coat the diatom biosilica frustule surface with 
a semiconductor thin film while preserving its shape and morphology [17]. Specifically, a cadmium sulphide (CdS) thin film was deposited, for the first time, onto the biosilica surface to impart optoelectronic properties to the frustule. CdS is a direct band gap II-VI semiconductor with an average band gap of $2.42 \mathrm{eV}$ at room temperature. It is widely used in photodetectors, solar cells, and many other optoelectronic device applications. The CdS/diatom biosilica nanocomposite structures, which consist of two-dimensional pore arrays ordered at the nano and submicron scales, may find potential application as sensors, photonic band gap materials, and a variety of other optoelectronic devices. A wide diversity in diatom species, each with a unique shape, size, pore size, and architecture, offers a huge selection for device and device applications $[18,19]$.

\section{Experimental}

Intact diatom biosilica was isolated from cell cultures of diatom Pinnularia $s p$. using aqueous hydrogen peroxide treatment as previously described [8]. A CBD batch reactor with a bath solution of $600 \mathrm{~mL}$ was used to coat CdS onto the surface of the intact diatom biosilica frustules. The bath solution contained cadmium chloride $\left(\mathrm{CdCl}_{2}\right.$, $0.004 \mathrm{~mol} / \mathrm{L}$ ) as a source of cadmium ions, ammonium chloride $\left(\mathrm{NH}_{4} \mathrm{Cl}, 0.04 \mathrm{~mol} / \mathrm{L}\right)$ buffer, thiourea $\left(\left(\mathrm{NH}_{2}\right)_{2} \mathrm{CS}\right.$, $0.04 \mathrm{~mol} / \mathrm{L})$ as source of sulphide ions, and (29.3 wt \%) ammonium hydroxide $\left(\mathrm{NH}_{4} \mathrm{OH}, 0.4 \mathrm{~mol} / \mathrm{L}\right)$, to maintain the $\mathrm{pH}$ at 11 . The precursor solutions were prepared separately as described by Chang [17]. The diatom frustule powder was added to the bath just after the addition of $\mathrm{NH}_{4} \mathrm{OH}$, which initiated the chemical bath deposition reaction. The temperature of the bath was maintained at $80^{\circ} \mathrm{C}$. After 10 minutes of deposition, the batch reactor was removed from the heat source and the bath solution was diluted with $800 \mathrm{~mL}$ of de-ionized water to quench the reaction. The supernatant was removed after about 10 minutes and the diatom frustules were washed with DI water and then stored in methanol. The chemical bath deposition of CdS thin film is based on the controlled precipitation of CdS in the bath. The slow release of the sulphide ions via the controlled hydrolysis of thiourea into the alkaline solution controls the precipitation reaction. When the ionic product, $\left[\mathrm{Cd}^{2+}\right]\left[\mathrm{S}^{2-}\right]$, exceeds the solubility product of CdS $\left(\approx 10^{-25}\right)$, the CdS precipitates at the surface of the substrate (frustules in this case) or in the solution according to the following reaction:

$$
\mathrm{Cd}^{2+}+\mathrm{S}^{2-} \longrightarrow \mathrm{CdS}(\mathrm{s})
$$

The overall reaction is given by:

$$
\begin{aligned}
\mathrm{Cd}\left(\mathrm{NH}_{3}\right)_{4}^{2+}+\mathrm{SC}\left(\mathrm{NH}_{2}\right)_{2} & +2 \mathrm{OH}^{-} \\
& \longrightarrow \mathrm{CdS}+\mathrm{CH}_{2} \mathrm{~N}_{2}+4 \mathrm{NH}_{3}+2 \mathrm{H}_{2} \mathrm{O}
\end{aligned}
$$

The surface morphology of the as-deposited CdS was analyzed using an FEI Sirion Field Emission Scanning Electron Microscope (FESEM). To prepare FESEM samples, one or two drops of diatom frustules dispersed in methanol were placed onto an ITO glass substrate, which was then fixed onto an $\mathrm{Al}$ stub. An accelerating voltage of $5 \mathrm{kV}$ was used for imaging. An FEI Tecnai F20 Transmission Electron Microscope (TEM) was used to characterize the structure and elemental composition of the CdS coating. To make the diatom frustules electron transparent for the TEM characterization, the CdS-coated diatom frustules were ultrasonicated for about 30 minutes to break them up into smaller fragments.

For photoluminescence (PL) measurements, the frustules were fixed onto a glass substrate by oxygen plasma treatment prior to CBD. Diatom frustules, dispersed in methanol, were placed onto a $2 \mathrm{~cm} \times 1 \mathrm{~cm}$ glass slide using a pipette and then air dried. SEM was used to ensure that the glass substrate was completely covered with diatom frustules. The frustules on glass were then subjected to oxygen plasma in FISCHIONE model 1020 plasma cleaner for about 1.5 hours to allow the diatom frustules to form chemical bonds with the glass substrate. The glass substrate containing the adhered diatom frustules was then placed vertically in the bath solution. After deposition, any homogeneously formed CdS nanoparticles were flushed out by washing with DI water. These procedures ensured that only the PL of the heterogeneously deposited CdS film itself was measured. The excitation source for photoluminescence measurements was a $337 \mathrm{~nm}$ $\mathrm{N}_{2} \mathrm{UV}$ laser. All PL measurements were carried out at room temperature.

\section{Results and Discussion}

3.1. Morphology and Structure. Figure 1 shows FESEM images for the typical surface morphology of intact frustule biosilica isolated from the diatom Pinnularia sp. Figures $1(\mathrm{a})-1(\mathrm{c})$ as well as intact diatom biosilica coated with CdS using the chemical bath deposition technique Figures $1(\mathrm{~d})-$ $1(\mathrm{i})$. Figures $1(\mathrm{~d})-1(\mathrm{~g})$ shows that the as-deposited $\mathrm{CdS}$ coating was dense and replicated the shape of the diatom frustule. Furthermore, there were no pinholes on the film, and the substrate surface coverage was compact, complete, granulated, and nanostructured. There are three known modes of heteroepitaxial growth, namely, the Frank-van der Merwe (or layer-by-layer), the Stranski-Krastanow (or island growth) and combination of the two called layer-by-layer plus island. In the layer-by-layer growth mode, the particles are more strongly bound to the substrate than to each other and in the island growth mode, the particles are strongly bonded to each other than to the substrate [20].

It was assumed that the growth of the film occurred by a layer-by-layer growth mode where the smallest stable nuclei condense and extend the deposit in two dimensions across a surface. Figure 1 showed that the CdS nanoparticles formed a two dimensional monolayer (thin film). This suggested that the CdS spherical nanoparticles were more strongly bound to the silica than to each other causing them to form a 2D structure (thin film due to layer-by-layer growth mode) instead of islands (3D structure due to island growth mode). Two experimental observations testify to the tight adherence of the CdS nanoparticles to the surface of the diatom frustules. Firstly, the CdS nanoparticles on the surface of the frustules remained intact after being subjected to 


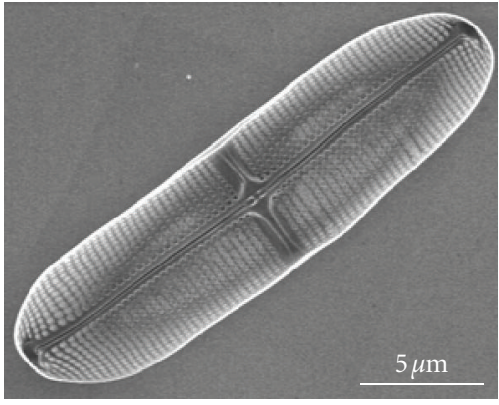

(a)

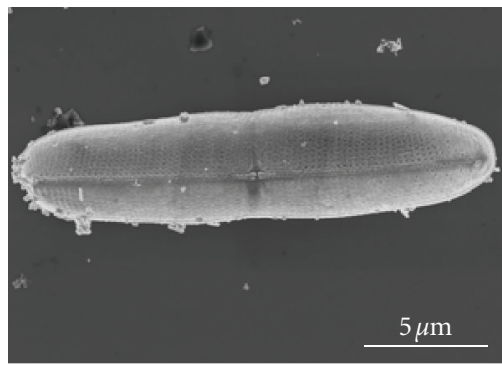

(d)

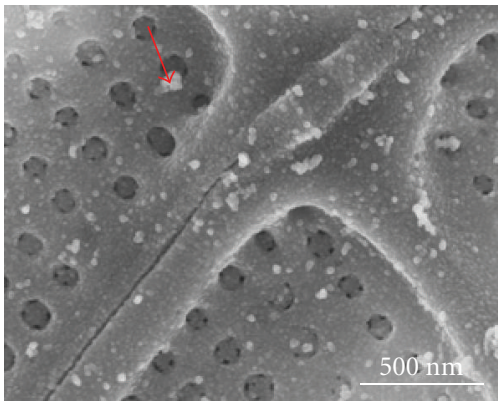

(g)

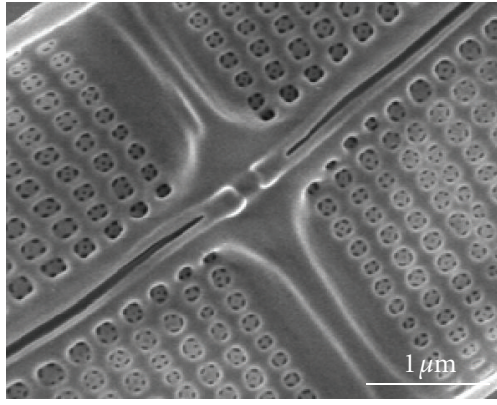

(b)

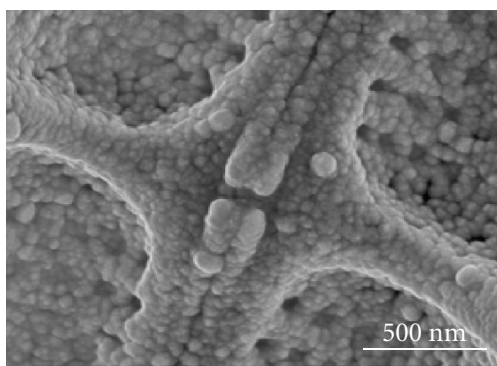

(e)

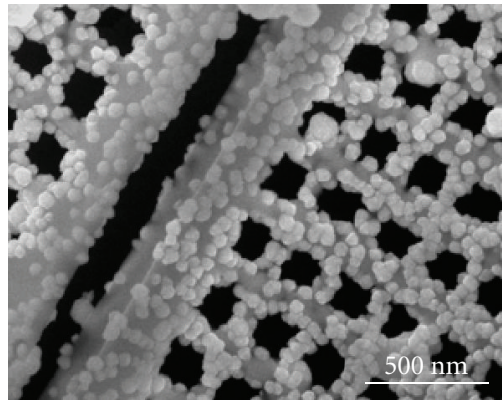

(h)

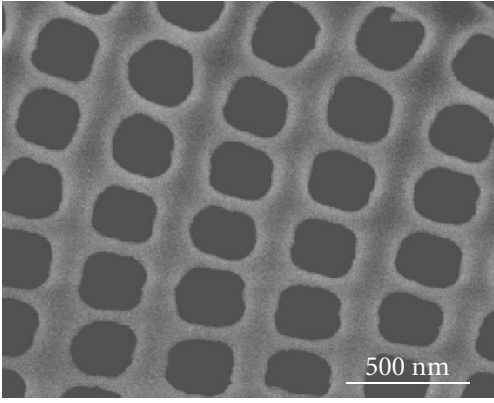

(c)

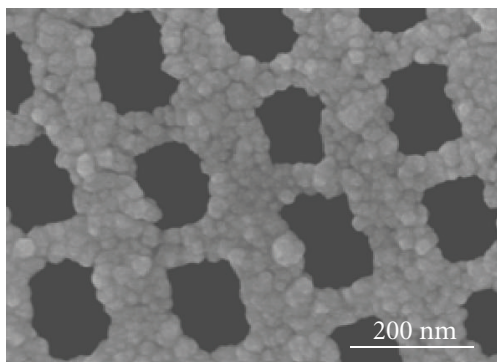

(f)

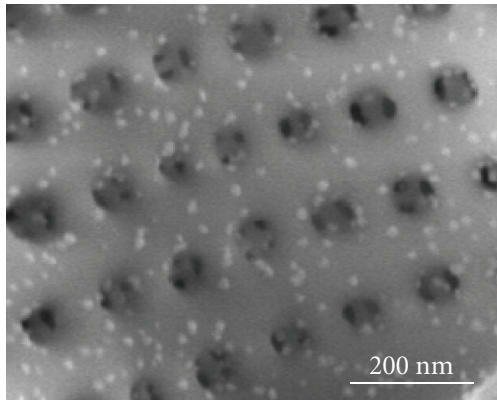

(i)

FIgURE 1: SEM images (a) Intact diatom Pinnularia sp., (b) Fine structures within pores are visible, (c) High resolution image of pore array with no fine structures, (d) Intact diatom coated with CdS, (e) CdS coating on a diatom with fine structures within the pores (f) CdS spherical particles clearly visible, (g)-(i) CdS deposited under different conditions (g) Precursor concentration of 1/16 the initial concentration, (h) Bath temperature at $70^{\circ} \mathrm{C}$ and (i) CdS deposited on diatom fixed onto a glass substrate.

high intensity ultrasonication for 30 minutes as previously mentioned in the experimental section. Secondly, the selfassembling or growth mode of the CdS particles (clusters) on the diatom surface also provides information on the adherence of the particles to the frustules and between the particles. In Figures 1(c) and 1(h) the fine structures within the diatom pores are absent. This is not unexpected because some fine structures may fall off during the removal of organic matter on the diatom cell mass by oxidation with aqueous hydrogen peroxide. Though the removal of organic matter from the diatom cell mass by hydrogen peroxide is a gentile process, some small features of the frustules may be damaged or removed during the oxidation process. However, most frustules retained the fine structures during the oxidation process. The fine structures are preserved during the deposition of CdS on the frustules by the CBD method (Figures $1(\mathrm{~g})$ and $1(\mathrm{i})$ ).
The optoelectronic, chemical and structural properties of nanomaterials are size-dependent. For instance, the absorption edge of CdS nanocrystals exhibits a blue shift due to quantum confinement effect [21]. The nanostructured CdS thin film was composed of spherical nanoparticles with a narrow particle size distribution (Figure 2). The particle size was measured using analySIS $(\mathbb{B}$ software. The average nanoparticle (cluster) size was $72 \pm 6 \mathrm{~nm}$. A few particles formed by a homogeneous precipitation reaction in the solution also adsorbed randomly onto the growing CdS thin film (shown by red arrow in Figure $1(\mathrm{~g})$ ). These particles were much larger than the nanoparticles heterogeneously formed on the diatom biosilica frustule surface.

The physical properties of the CdS thin film depended upon the chemical bath deposition conditions, including precursor concentration, bath temperature, and deposition time. Figure $1(\mathrm{~g})$ shows that the size of the spherical CdS 


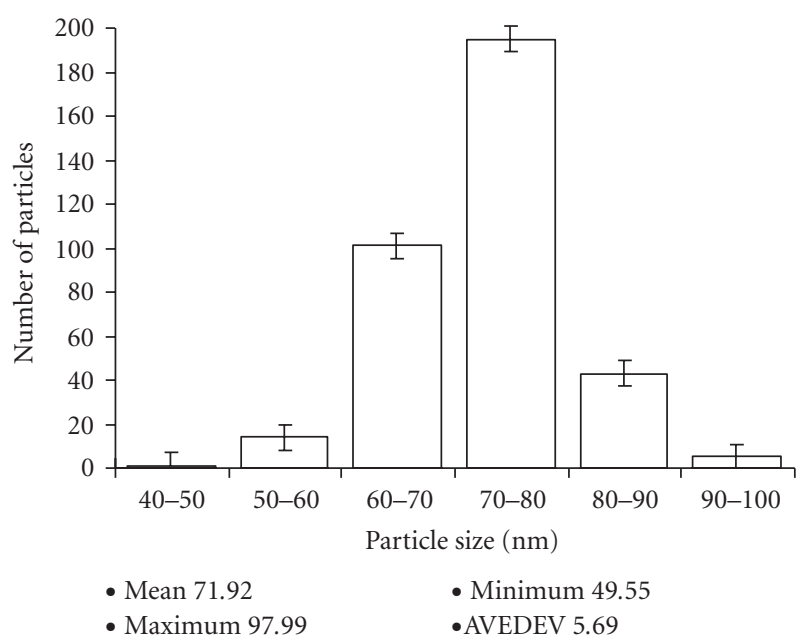

FIGURE 2: Bar graph showing nanoparticles size distribution.

nanoparticles decreased with decreasing cadmium chloride precursor concentration in the chemical deposition bath. Most likely, increasing the cadmium precursor concentration increased the extent of adsorption of the chemical bath reagents and their complexes onto the frustule surface. This lead to an increase in the heterogeneous precipitation of CdS onto the surface, and was accompanied by a subsequent increase in particle size. Furthermore, the appearance of the CdS films changed as the precursor solution concentration increased, from a pale yellow color for the asgrown layer prepared with a low precursor concentration of $0.00025 \mathrm{~mol} / \mathrm{L}$ of $\mathrm{CdCl}_{2}$, to a strong orange color for films prepared with a high precursor concentration of $0.004 \mathrm{~mol} / \mathrm{L}$ of $\mathrm{CdCl}_{2}$ (16x initial precursor concentration). This change in color was attributed to the change in the size of the CdS nanoparticles.

It was also found that the solution bath temperature and deposition time affected the CdS particle size and frustule surface coverage. Frustule surface coverage by CdS was incomplete at temperatures at or below $70^{\circ} \mathrm{C}$, even for an extended deposition time of 5 hours (Figure 1(h)). However, temperatures above $70^{\circ} \mathrm{C}$ increased the extent of $\mathrm{CdS}$ deposition. The frustule surface coverage was incomplete for short deposition times of about 7 minutes or less. The particle size was found to decrease slightly with decreasing temperature and short deposition times.

In order to achieve a more direct insight into the internal structural properties of the CdS thin film, TEM analysis was performed. Figure 3 shows TEM images of the typical fine structure of the frustule biosilica from the diatom Pinnularia $s p$ before and after the CBD process. A TEM image of the diatom frustule microstructure before CBD is presented in Figure 3(a). As shown in Figure 3(b), after the CBD of CdS, the entire frustule microstructure is coated with spherical nanoparticles compactly deposited onto the frustule surface. In Figure 3(c), the randomly oriented crystal grains show that the CdS thin film is polycrystalline. A polycrystalline material is made up of grains of crystalline material where the grains are randomly oriented relative to each other. In
HRTEM (Figures 3(c)-3(d)), grains appear as a regions with lattice fringes oriented in a random directions. A region with lattice fringes in a particular direction is a grain. The average grain size is about $3 \pm 1 \mathrm{~nm}$. Fringe spacing of CdS obtained from Figure 3(c) are $0.367 \mathrm{~nm}$ in the [110] direction and $0.378 \mathrm{~nm}$ at $120^{\circ}$ to the [110] direction.

The diffraction pattern (Figure 3(c) insert) is composed of sharp, spotty, discontinuous rings which corroborates that the thin film is polycrystalline with well-defined crystalline grains. The (100), (002) or (111), (110), (200), (201), (203), (300) or (422), and (213) planes were observed in the SAD pattern which largely confirms that the CdS thin film was hexagonal. The interplanar distances (d) for the (hkl) planes were calculated using the relation $d=L \lambda / R$ where $L$ is the camera constant, $\lambda$ is the electron wavelength $(=0.00251 \mathrm{~nm})$ and $\mathrm{R}$ is the radius of the diffracted ring. The interplanar distances calculated from diffraction patterns were $0.3526 \mathrm{~nm}, 0.3383 \mathrm{~nm}, 0.2077 \mathrm{~nm}, 0.1791 \mathrm{~nm}, 0.1730 \mathrm{~nm}$, $0.1381 \mathrm{~nm}$ and $0.1195 \mathrm{~nm}$ and $0.1169 \mathrm{~nm}$. Planar defects are also observed in the CdS thin film. Figure $3(\mathrm{~d})$ shows the stacking faults near grain boundary of the (001) plane and the subsequent lattice structure distortions. In Figures 3(c) and $3(\mathrm{~d})$, the abrupt changes in crystallographic direction of the lattice are clearly visible. The chemical composition of a CdS-coated frustule is shown by the TEM EDX spectrum in Figure 4. Si and $\mathrm{O}$ are from the diatom biosilica whereas $\mathrm{Cd}$ and $\mathrm{S}$ and are from the deposited CdS thin film.

3.2. Photoluminescence. Figure 5 shows the PL spectra of both the uncoated frustules (A) centered at $457 \mathrm{~nm}$ and the CdS-coated (Insert (B)) frustules. Non-coated diatom frustules (A) possess some intrinsic blue photoluminescence, which is attributed to a variety of surface defects [22]. The broad PL peak spans from about $370 \mathrm{~nm}$ to about $700 \mathrm{~nm}$, which makes this material unsuitable for applications that require narrow emission and high sensitivity, such as photodetectors. However, when the frustules were coated with CdS, a much sharper PL yellow emission peak ( $560 \mathrm{~nm}$ to $620 \mathrm{~nm})$ centered at $588 \mathrm{~nm}(2.11 \mathrm{eV})$ emerged (Figure 5b). This new peak is associated with radiative transitions from the donor levels, arising from Cd atoms located in interstitial sites, to the valence band [23]. A tiny peak centered at $665 \mathrm{~nm}$ $(1.87 \mathrm{eV})$ was also observed on the CdS-coated diatom frustules. This red band is ascribed to either sulphur vacancy states or transition of bound electrons from surface states to the valence band [24]. The average particle diameter of the CdS nanoparticles for the PL samples used to obtain results in Figure 5 was about $35 \pm 6 \mathrm{~nm}$. The $\mathrm{CdS}$ nanoparticles deposited directly onto the glass substrate were smaller and less dense than the CdS nanoparticles on the diatoms. This suggests that precipitation of $\mathrm{CdS}$ on the frustules was more favored than the precipitation on the glass substrate. SEM analysis showed that the regions with CdS-coated frustules had a deeper color contrast than those with no or less frustules. The CdS nanoparticle density onto the surface of the frustules for the specimen used to obtain the PL signal in Figure 5 (B) was less than $25 \%$ as shown in Figure 1(i) and did not have any considerable effect the $457 \mathrm{~nm}$ PL signal. 


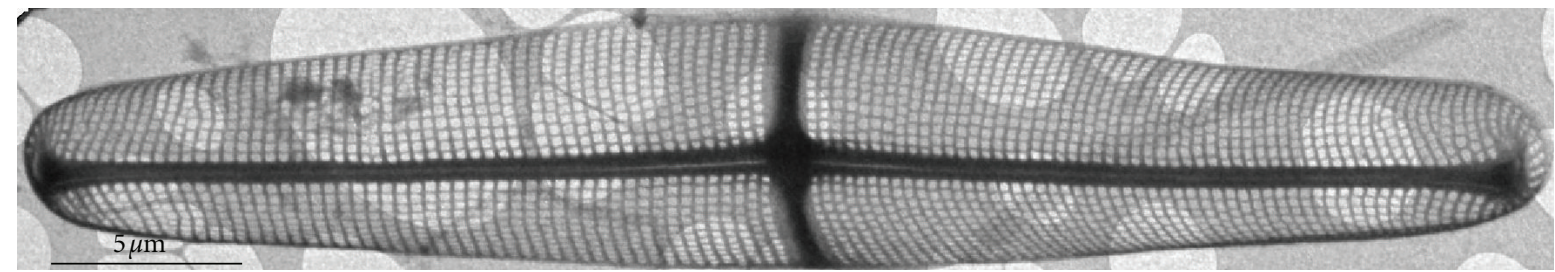

(a)

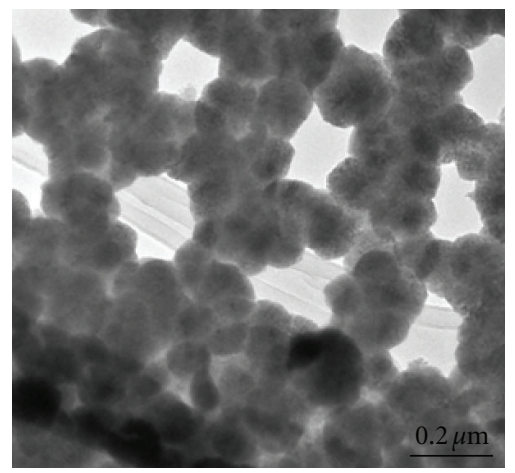

(b)

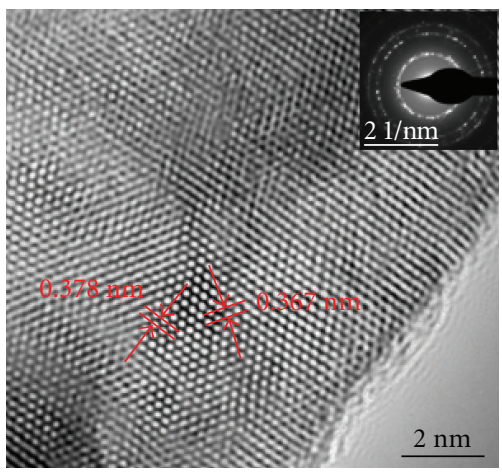

(c)

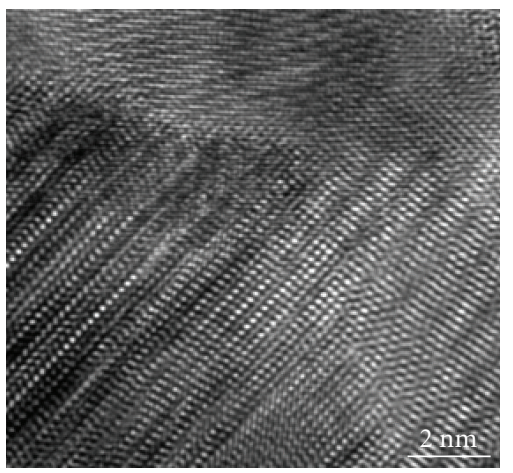

(d)

Figure 3: TEM images (a) Intact diatom frustule with no CdS coating, (b)-(d) CdS coated frustule; (a) Microstructure, (c) Nanostructure shows lattice fringes; insert shows the corresponding diffraction pattern, and (d) Stacking faults near the grain boundary.

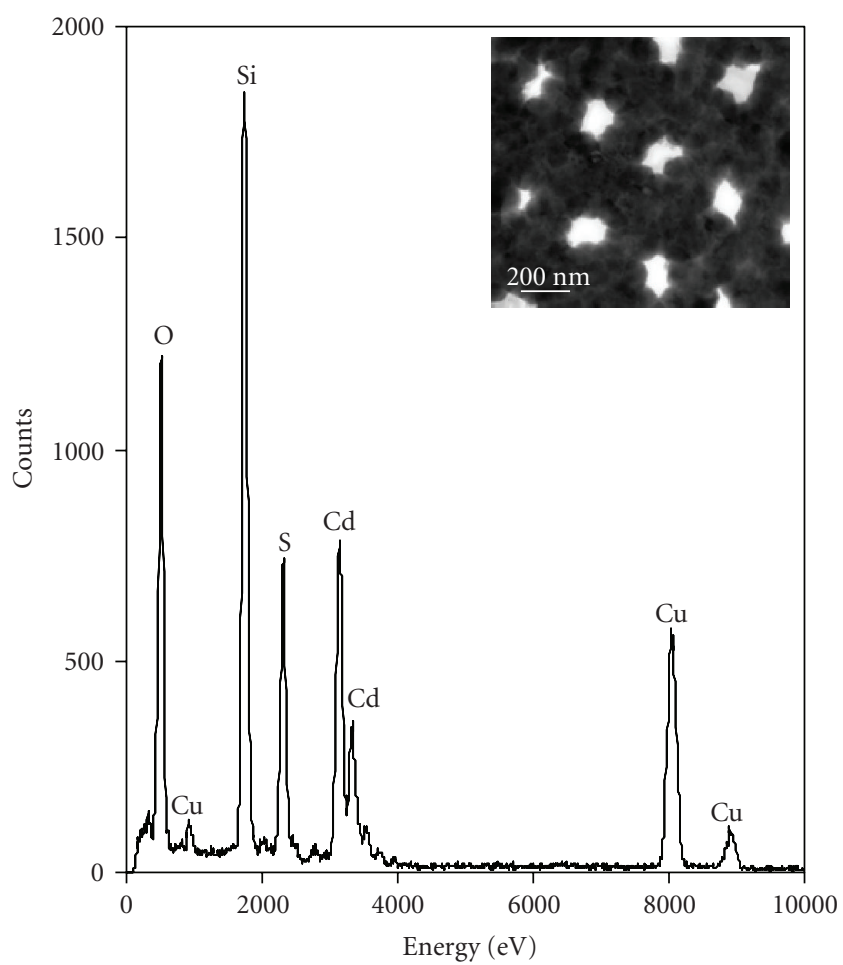

FIgURE 4: TEM EDX spectrum details the chemical composition of the CdS-coated frustule shown in the insert. The red dot is the spot where the chemical composition was taken. The $\mathrm{Cu}$ peak is an artifact of the TEM grid.

However, a significant change in the frustules PL properties was observed when the CdS nanoparticle coverage onto the frustules' surface was complete. The CdS frustule coverage

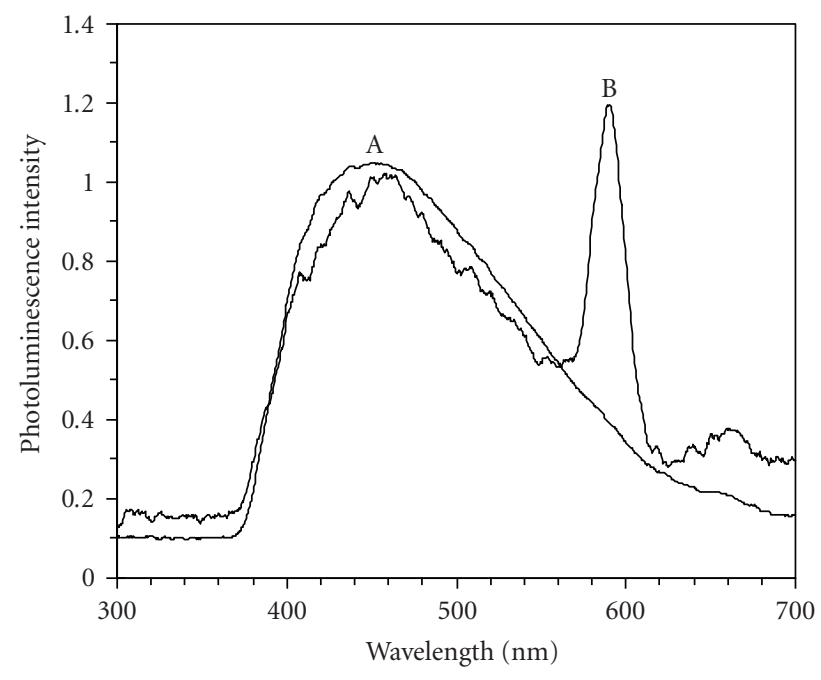

FIGURE 5: Photoluminescence spectra of diatom frustules. (A) refers to diatom biosilica before CdS deposition, (B) refers to diatom biosilica after CdS deposition.

was improved by either increasing the bath deposition temperature to about $100^{\circ} \mathrm{C}$ or by doubling the precursor concentrations.

Figure 6 showed that the intrinsic photoluminescence of the frustules were totally quenched as shown by the disappearance of the broad PL signal from the diatom silica which was centered at $457 \mathrm{~nm}$. This suggests that the PL signals are coming solely from the $\mathrm{CdS}$ thin film deposited on the biosilica and can therefore be interpreted by considering PL properties of CdS thin films. This result is in agreement with results obtained by Andsager et al. who showed how 


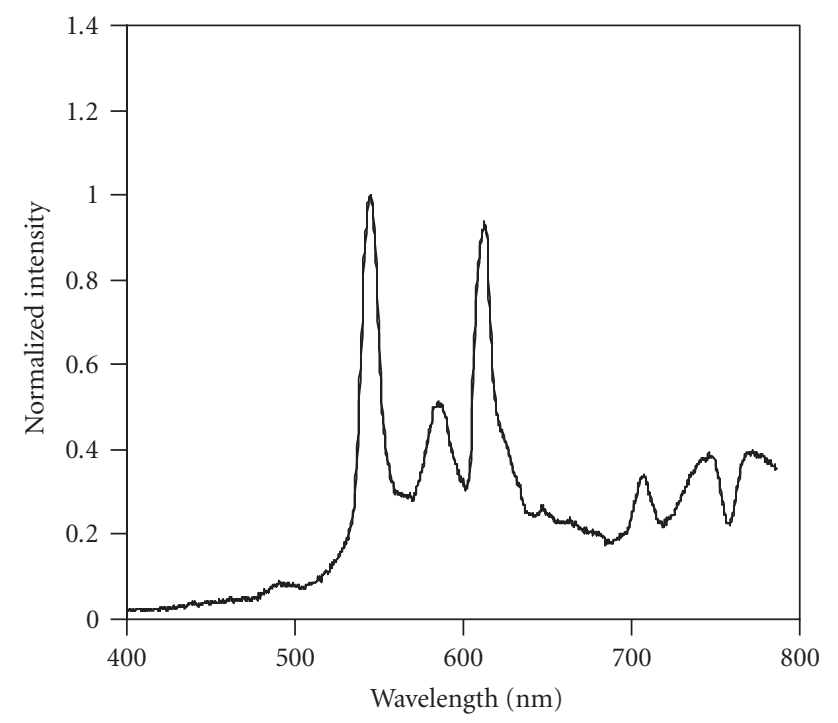

Figure 6: Photoluminescence spectrum of diatom frustules with complete CdS coverage onto the surface of the frustule.

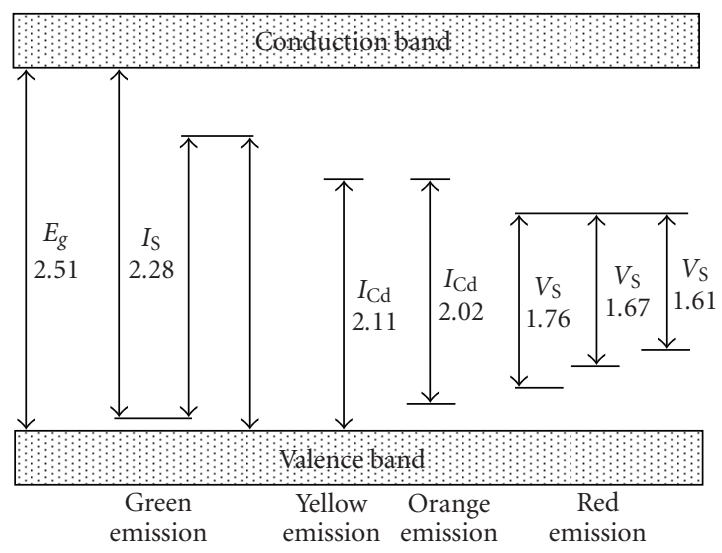

Figure 7: Schematic energy level diagram for the different electronic transitions observed in CdS deposited on diatom frustules.

PL was affected by the deposition of metals upon silica [25]. Metals such as copper, silver and gold were found to quench the PL when deposited on luminescent porous silica.

Figure 7 shows the possible emission bands observed in the visible region for the as-deposited CdS thin films. Several interesting prominent PL peaks spanning the visible spectral region were observed. The green emission peak at about $495 \mathrm{~nm}(2.51 \mathrm{eV})$ corresponds to the CdS direct band gap. This was further confirmed by separate optical transmission experiments (results not included in this paper). There are three explanations about the origins of the green emission band, namely, recombination of trapped electrons from a donor level with free holes, or recombination of free electrons from the conduction band with holes in the acceptor levels and recombination of electrons from a donor level with holes trapped on the acceptor level $[26,27]$. The green emission band peak at $545 \mathrm{~nm}(2.28 \mathrm{eV})$ is attributed to excitation from interstitial sulphur $\left(\mathrm{I}_{S}\right)$ to conduction band.
The yellow band emission peak at $588 \mathrm{~nm}$, as previously explained, is due to transitions from the interstitial cadmium $\left(\mathrm{I}_{\mathrm{Cd}}\right)$ donor level to the valence band. An orange band emission peak was observed at about $613 \mathrm{~nm}(2.02 \mathrm{eV})$. This peak is ascribed transitions of $\mathrm{I}_{\mathrm{Cd}}$ donor level to acceptor levels. The intensity of the green $(2.28 \mathrm{eV})$ and the orange emission peaks was much stronger than that of the yellow emission peak. Three prominent red emission peaks were observed at $708 \mathrm{~nm}(1.76 \mathrm{eV}), 745 \mathrm{~nm}(1.67 \mathrm{eV})$ and $772 \mathrm{~nm}(1.61 \mathrm{eV})$. These are ascribed to sulphur vacancies $\left(V_{S}\right)$ or surface states as previously said. The surface states increases with improved $\mathrm{CdS}$ coverage onto the frustules and thus led to appearance of the red emission bands with enhanced intensity. The $665 \mathrm{~nm}$ peak was not observed for samples with complete biosilica (frustule) substrate coverage. It is important to note that increasing CdS coverage onto frustules by increasing deposition temperature or by increasing precursor concentrations also caused an increase in cluster size from about $35 \mathrm{~nm}$ to about $100 \mathrm{~nm}$ and hence increased CdS thin film thickness. Tsai et al showed that the peak positions of the red and yellow emission bands were blue-shifted as the CdS film become thinner [28]. He also reported that the intensity of the emissions peaks was affected by the grain size.

\section{Conclusion}

In conclusion, this study shows that a simple and inexpensive chemical deposition process can be utilized to coat intricately patterned diatom frustules biosilica with optoelectronic semiconductor thin films. Specifically, biosilica frustules from the diatom Pinnularia sp. were coated with a polycrystalline CdS thin film, and photoluminescence measurements showed that the highly ordered structure of the diatom frustules now possessed a sharp yellow emission band centered at $2.11 \mathrm{eV}$ for $\mathrm{CdS}$ nanoparticles with a density of less than $25 \%$ on frustules surface. The photoluminescence was found to depend on the morphology and silica coverage of CdS onto the biosilica. Green, yellow, orange, and red emission bands were observed for high density of CdS nanoparticles on frustules' surface. The origins of the photoluminescent spectra were explained successfully on the basis of the band theory and native defects. The study illustrates the exciting opportunities for manipulating the structure and properties of diatom frustules on a nanometer scale using chemical bath deposition techniques. The use of diatom frustules as biotemplates to produce micro-to nanostructures with controllable optoelectronic properties opens the possibility of fabricating tunable optoelectronic sensors and device.

\section{References}

[1] M. R. Weatherspoon, M. B. Dickerson, G. Wang, et al., "Thin, conformal, and continuous $\mathrm{SnO}_{2}$ coatings on hydroxylamplified biosilica (diatom) templates via layer-by-layer alkoxide deposition," Angewandte Chemie International Edition, vol. 46, no. 30, pp. 5724-5727, 2007.

[2] Y. Xia and N. J. Halas, "Shape-controlled synthesis and surface plasmonic properties of metallic nanostructures," MRS Bulletin, vol. 30, no. 5, pp. 338-343, 2005. 
[3] L. Vayssieres, "On the design of advanced metal oxide nanomaterials," International Journal of Nanotechnology, vol. 1, no. 1-2, pp. 1-41, 2004.

[4] J. Schilling, J. White, A. Scherer, G. Stupian, R. Hillebrand, and U. Gösele, "Three-dimensional macroporous silicon photonic crystal with large photonic band gap," Applied Physics Letters, vol. 86, no. 1, Article ID 011101, 3 pages, 2005.

[5] G. Zhang, T. Zhang, X. Lu, W. Wang, J. Qu, and X. Li, "Controlled synthesis of $3 \mathrm{D}$ and $1 \mathrm{D}$ nickel nanostructures using an external magnetic field assisted solution-phase approach," The Journal of Physical Chemistry C, vol. 111, no. 34, pp. 12663-12668, 2007.

[6] T. Qin, T. Gutu, J. Jiao, C. Chang, and G. L. Rorrer, "Biological fabrication of photoluminescent nanocomb structures by metabolic incorporation of germanium into the biosilica of the diatom Nitzschia frustulum," ACS Nano, vol. 2, no. 6, pp. 1296-1304, 2008.

[7] M. Sumper and E. Brunner, "Learning from diatoms: nature's tools for the production of nanostructured silica," Advanced Functional Materials, vol. 16, no. 1, pp. 17-26, 2006.

[8] C. Jeffryes, T. Gutu, J. Jiao, and G. L. Rorrer, "Focus section: peptide-mediated deposition of nanostructured $\mathrm{TiO}_{2}$ into the periodic structure of diatom biosilica," Materials Research Society, vol. 23, no. 12, pp. 3255-3262, 2008.

[9] S. Dudley, T. Kalem, and M. Akinc, "Conversion of $\mathrm{SiO}_{2}$ diatom frustules to $\mathrm{BaTiO}_{3}$ and $\mathrm{SrTiO}_{3}$," Journal of the American Ceramic Society, vol. 89, no. 8, pp. 2434-2439, 2006.

[10] D. Losic, G. Triani, P. J. Evans, A. Atanacio, J. G. Mitchell, and N. H. Voelcker, "Controlled pore structure modification of diatoms by atomic layer deposition of $\mathrm{TiO}_{2}$," Journal of Materials Chemistry, vol. 16, no. 41, pp. 4029-4034, 2006.

[11] M. R. Weatherspoon, S. M. Allan, E. Hunt, Y. Cai, and K. H. Sandhage, "Sol-gel synthesis on self-replicating singlecell scaffolds: applying complex chemistries to nature's 3-D nanostructured templates," Chemical Communications, no. 5, pp. 651-653, 2005.

[12] H. E. Townley, K. L. Woon, F. P. Payne, H. White-Cooper, and A. R. Parker, "Modification of the physical and optical properties of the frustule of the diatom Coscinodiscus wailesii by nickel sulfate," Nanotechnology, vol. 18, no. 29, Article ID 295101, 5 pages, 2007.

[13] Y. Cai, S. M. Allan, K. H. Sandhage, and F. M. Zalar, "Three-dimensional magnesia-based nanocrystal assemblies via low-temperature magnesiothermic reaction of diatom microshells," Journal of the American Ceramic Society, vol. 88, no. 7, pp. 2005-2010, 2005.

[14] D.-H. Lee, T. Gutu, C. Jeffryes, G. L. Rorrer, J. Jiao, and C. Chang, "Nanofabrication of green luminescent $\mathrm{Zn}_{2} \mathrm{SiO}_{4}: \mathrm{Mn}$ using biogenic silica," Electrochemical and Solid-State Letters, vol. 10, no. 7, pp. K13-K16, 2007.

[15] D.-H. Lee, W. Wang, T. Gutu, et al., "Biogenic silica based $\mathrm{Zn}_{2} \mathrm{SiO}_{4}: \mathrm{Mn}^{2+}$ and $\mathrm{Y}_{2} \mathrm{SiO}_{5}: \mathrm{Eu}^{3+}$ phosphor layers patterned by inkjet printing process," Journal of Materials Chemistry, vol. 18, no. 31, pp. 3633-3635, 2008.

[16] C. Jeffryes, T. Gutu, J. Jiao, and G. L. Rorrer, "Two-stage photobioreactor process for the metabolic insertion of nanostructured germanium into the silica microstructure of the diatom Pinnularia sp," Materials Science and Engineering $C$, vol. 28, no. 1, pp. 107-118, 2008.

[17] Y.-J. Chang, P. H. Mugdur, S.-Y. Han, A. A. Morrone, S. O. Ryu, T.-J. Lee, and C.-H. Changa, "Nanocrystalline CdS MISFETs fabricated by a Novel Continuous Flow Microreactor," Electrochemical and Solid-State Letters, vol. 9, no. 5, pp. G174-G177, 2006.
[18] J. Parkinson, Y. Brechet, and R. Gordon, "Centric diatom morphogenesis: a model based on a DLA algorithm investigating the potential role of microtubules," Biochimica et Biophysica Acta, vol. 1452, no. 1, pp. 89-102, 1999.

[19] R. W. Drum and R. Gordon, "Star Trek replicators and diatom nanotechnology," Trends in Biotechnology, vol. 21, no. 8, pp. 325-328, 2003.

[20] D. J. Eaglesham and M. Cerullo, "Dislocation-free StranskiKrastanow growth of Ge on Si(100)," Physical Review Letters, vol. 64, no. 16, pp. 1943-1946, 1990.

[21] D. Kaushik, R. R. Singh, M. Sharma, D. K. Gupta, N. P. Lalla, and R. K. Pandey, "A study of size dependent structure, morphology and luminescence behavior of CdS films on $\mathrm{Si}$ substrate," Thin Solid Films, vol. 515, no. 18, pp. 7070-7079, 2007.

[22] T. Qin, T. Gutu, J. Jiao, C. Chang, and G. L. Rorrer, "Photoluminescence of silica nanostructure from bioreactor culture of marine diatom Nitzschia frustulum," Journal of Nanoscience and Nanotechnology, vol. 8, no. 5, pp. 2392-2398, 2008.

[23] J. Aguilar-Hernández, G. Contreras-Puente, A. MoraleAcevedo, et al., "Photoluminescence and structural properties of cadmium sulphide thin films grown by different techniques," Semiconductor Science and Technology, vol. 18, no. 2, pp. 111-114, 2003.

[24] M. D. Archbold, D. P. Halliday, K. Durose, et al., "Development of low temperature approaches to device quality CdS: a modified geometry for solution growth of thin films and their characterisation," Thin Solid Films, vol. 515, no. 5, pp. 29542957, 2007.

[25] D. Andsager, J. Hilliard, J. M. Hetrick, L. H. Abuhassan, M. Plisch, and M. H. Nayfeh, "Quenching of porous silicon photoluminescence by deposition of metal adsorbates," Journal of Applied Physics, vol. 74, no. 7, pp. 4783-4785, 1993.

[26] R. Lorada-Morales, O. Zelaya-Angel, and G. Torres-Delgado, "On the yellow-band emission in the CdS films," Applied Physics A, vol. 73, no. 1, pp. 61-65, 2001.

[27] K. S. Ramaiah, R. D. Pilkington, A. E. Hill, R. D. Tomlinson, and A. K. Bhatnagar, "Structural and optical investigations on CdS thin films grown by chemical bath technique," Materials Chemistry and Physics, vol. 68, no. 1-3, pp. 22-30, 2001.

[28] C. T. Tsai, D. S. Chuu, G. L. Chen, and S. L. Yang, "Studies of grain size effects in rf sputtered CdS thin films," Journal of Applied Physics, vol. 79, no. 12, pp. 9105-9109, 1996. 

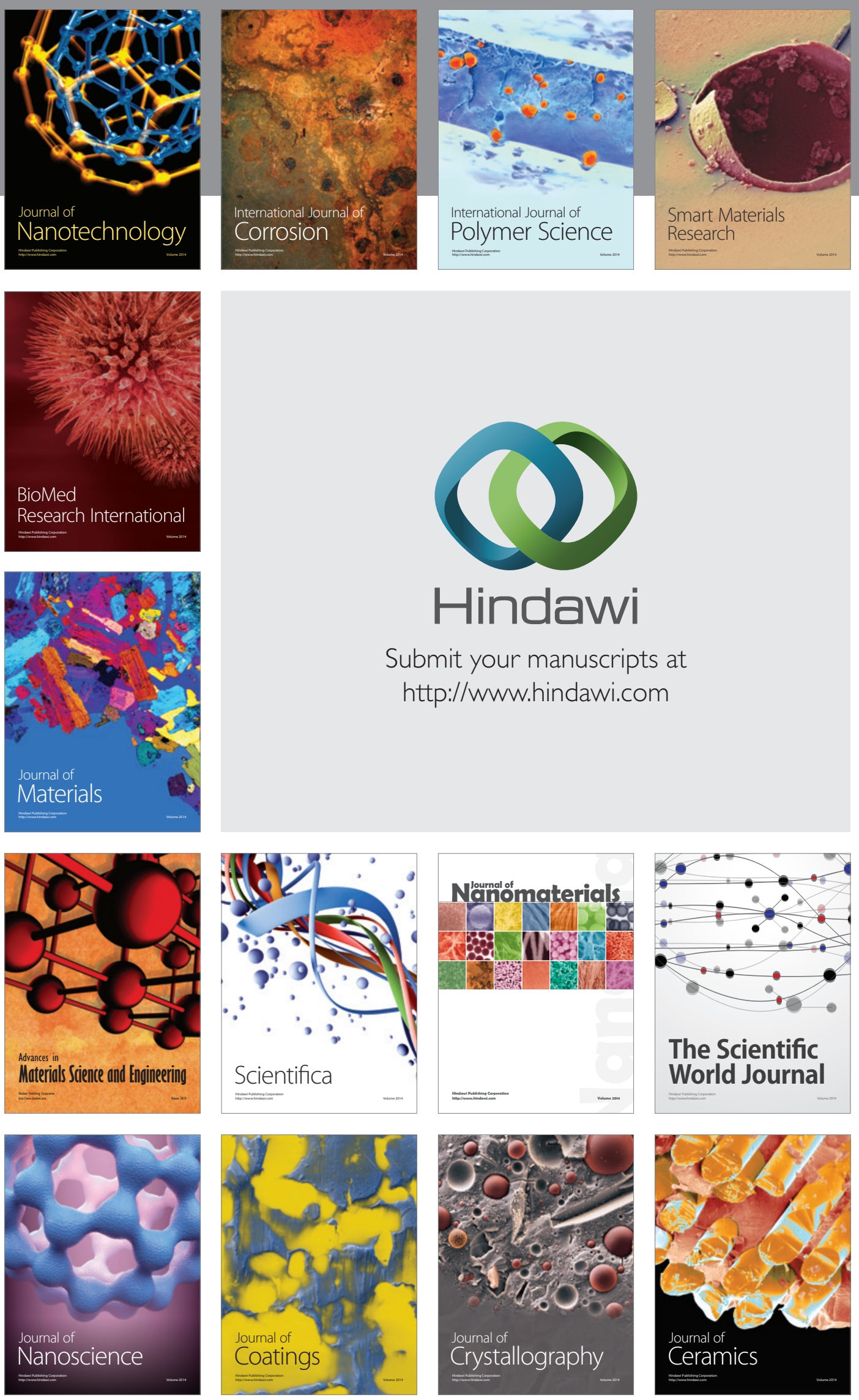

The Scientific World Journal

Submit your manuscripts at

http://www.hindawi.com

\section{World Journal}

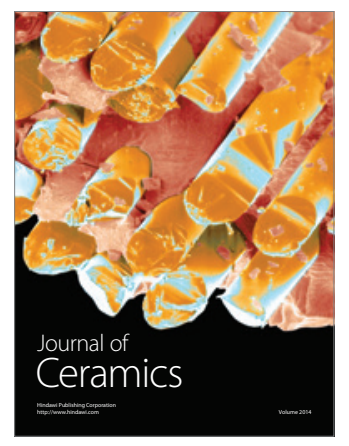

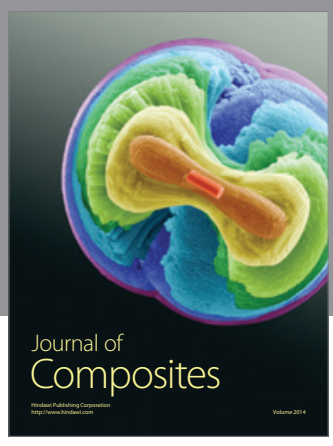
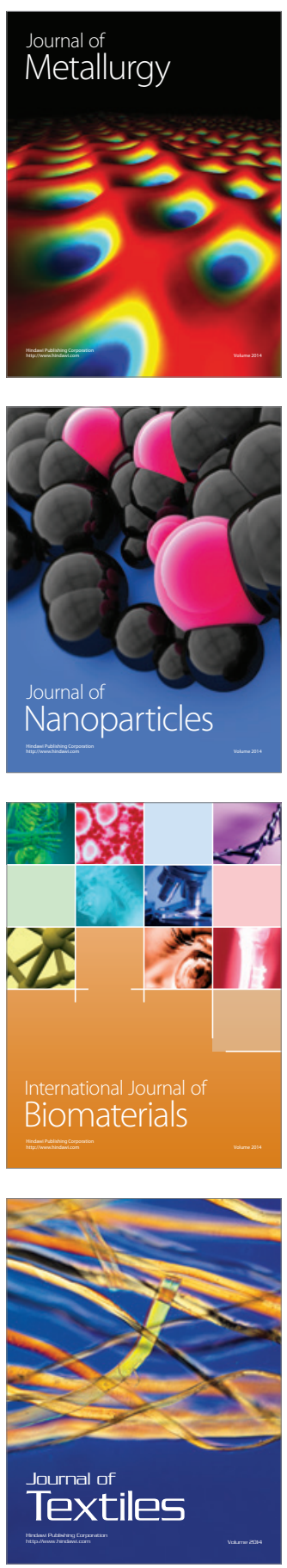